\title{
Hyperoxaluria Induces Oxidative DNA Damage and Results in Renal Tubular Epithelial Cell Apoptosis: A Clue to the Pathogenesis of Urolithiasis
}

\author{
Hasan Aydin ${ }^{1 *}$, Faruk Yencilek ${ }^{2}$, Jale Çoban ${ }^{3}$ and Hasbey Hakan Koyuncu ${ }^{2}$ \\ ${ }^{1}$ Department of Endocrinology and Metabolism, Yeditepe University Medical Faculty, Turkey \\ ${ }^{2}$ Department of Urology, Yeditepe University Medical Faculty, Turkey \\ ${ }^{3}$ Department of Biochemistry, Yeditepe University Medical Faculty, Turkey
}

*Corresponding author: Hasan Aydin, Yeditepe Universitesi Hastanesi, İcerenkoy Mahallesi, Hastane Yolu Sokak, No: 102, Atasehir, Istanbul 34752, Turkey

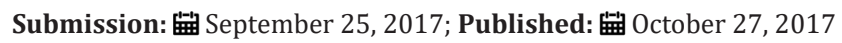

\begin{abstract}
Renal tubular injury is an essential component of renal stone disease. Several mechanisms were proposed to explain how renal tubular injury occurs. But the exact mechanism is still obscure. Oxidative damage to DNA is one of the universal mechanisms of cellular injury. Although increase in oxidative DNA damage markers was reported in urolithiasis, none of them are enough to prove the direct effect of calcium oxalate crystals. The aim of this study was to investigate whether oxidative DNA damage and renal tubular cell apoptosis markers can be induced by hyperoxaluria in an animal model. A total of 16 Sprague Dowley rats have been included into study. Group I ( $n=8)$ : Hyperoxaluria-induced group; Group II ( $n=8)$ : Control group. Twenty four hour urine samples were collected at 24 hour, 14 day and 28 day after hyperoxaluric diet for the analysis of 8-hydroxydeoxyguanosine (8$\mathrm{OHG}$ ) and oxalate excretion. Rats were euthanized at $28^{\text {th }}$ day and right kidney was taken for immunohistochemical analysis for apoptosis markers Fas, TNF- $\alpha$. Compared to controls, 8-OHdG excretion was found to be higher in hyperoxaluric group $(\mathrm{p}<.05)$. It began to rise early at 24 -hour samples and maintained the level throughout 28-day period. It was positively correlated with urinary oxalate excretion $(\mathrm{p}=.03, \mathrm{r}=.53)$ and renal tubular epithelial cell apoptosis markers $(\mathrm{p}=.007, \mathrm{r}=.710)$. Results indicate hyperoxaluria induced oxidative damage to DNA mediates renal tubular injury. This may contribute to the pathophysiology of renal stone disease and help to explain its relationship with other systemic diseases.
\end{abstract}

Keywords: Hyperoxaluria; Apoptosis; 8-hydroxydeoxyguanosine; Oxidative DNA damage; Urolithiasis

\section{Introduction}

Reactive oxygen species (ROS) are oxygen containing molecules which are produced under normal cellular metabolism and balanced with antioxidant mechanisms of the body in physiological states. Exposure to external events such as radiation, heavy metals, and infectious agents lead to an increase in generation of ROS resulting with oxidation of cellular components, activation of cytoplasmic/nuclear signal transduction pathways, modulation of gene and protein expression and alteration of DNA polymerase activity [1]. Damage to DNA is a well-known result of oxidative stress and several classes of products were identified and 8-hydroxyadenine (8-OH-Ade), 8-hydroxyguanine (8-OH-Gua; and its deoxynucleoside equivalent, 8-OH-dG), 5,6-dihydroxy-5,6dihydrothymine (thymine glycol, $\mathrm{Tg}$ ) and ring-opened lesions: 4,6-diamino-5-formamidopyrimidine (FapyAde) and 2,6-diamino4-hydroxy-5-formamidopyrimidine (FapyGua) are the best known examples [2,3]. The most commonly used markers of oxidative DNA damage in human is the excretion of 8-hydroxydeoxyguanosine (8OHdG) into urine.
Several environmental pollutants that are known to damage DNA have been studied for the effect on urinary 8-OHdG excretion rate. Exposure to smoking [4], benzene [5], styrene [6], asbestos [7], chromium [8] and polyaromatic hydrocarbons [9] had increased urine 8-OHdG excretion. It has not only studied as a biomarker of endogenous oxidative DNA damage but also widely used as a risk factor for many diseases such as cancer [10], diabetes mellitus [11], Alzheimer's disease [12], Parkinson disease [13], chronic hepatitis [14], systemic lupus erythematosus [15], ulcerative colitis [16], atherosclerosis [17], transplantation [18], and ageing [19].

Renal tubular injury is an essential component of renal stone disease. Different mechanisms were proposed to explain how renal tubular injury occurs. Widely studied and generally accepted mechanism is via oxidative stress. There are several studies demonstrating this relationship [20-22]. It is hypothesized that hyperoxaluria directly induces oxidative stress to cause renal tubular injury and any disease state such as obesity, diabetes mellitus, metabolic syndrome etc. that induce oxidative stress 
in turn causes renal tubular injury and increases renal stone prevalence in these disorders [23].

Increase in oxidative stress in turn causes damage to DNA. On the other hand, few studies investigated the link in urolithiasis with inconclusive results. Urinary $8-\mathrm{OHdG}$ was studied in 30 stone formers and compared to healthy controls elevated levels were observed [24]. It is also documented in another small size study that $8-\mathrm{OHdG}$ is increased together with pro inflammatory cytokines, acute inflammation markers, adhesion molecules and urinary micro albumin in 33 patients with urolithiasis [25]. It is also documented in renal biopsies obtained during surgery done for renal stone disease and shown an overexpression of 8-0HdG in the nucleus of renal tubular cells in patients with urolithiasis compared to controls and the effect was relevant only for calcium oxalate stone disease but not uric acid stones [26]. None of the studies are conclusive on the direct effect of calcium oxalate crystals on the development of oxidative DNA damage. For this reason, this study was conducted as to demonstrate direct effect of hyperoxalyuria on urine 8-hydroxydeoxyguanosine excretion.

\section{Materials and Methods}

\section{Study population}

A total of 16 Sprague-Dawley rats weighing 200 to 250 gram were included in the study, which was done in accordance with accepted standards of human animal care and use, as deemed appropriate by the Yeditepe University Medical Faculty animal care and use ethical committee. Rats were housed in a specific pathogenfree room with an alternating 12 hours of light and darkness at a constant mean \pm SD temperature of $23^{\circ} \mathrm{C} \pm 1^{\circ} \mathrm{C}$ and $55 \% \pm 5 \%$ humidity. All rats had free access to distilled water and were fed 15 gram per day per rat of diet, which is the minimum average food intake of rats during acclimatization. All animals were screened urinalysis and microscopic examination for possible urinary tract and parasitic infections, which may ultimately alter the presence and degree of hyperoxaluria induced renal parenchymal alterations during study procedures. No rat had any evidence of infection and no specific treatment was nee

\section{Procedures}

The animals were then divided into 2 groups of 8 each. Group 1 (hyperoxaluric group) was given a hyperoxaluria inducing diet of .75\% ethylene glycol in distilled drinking water for 2 weeks. Group 2 was control group. No specific medication was given except feeding with distilled water. Rats in intervention group were evaluated 24 hour after ethylene glycol administration, at $14^{\text {th }}$ day and at study end, $28^{\text {th }}$ day for urine excretion of oxalate and 8-OHdG. Time intervals were selected in reference to previous studies $[7,22,27]$. The rats were transferred to individual metabolic cages and $24 \mathrm{~h}$ urine samples were collected in a $50 \mathrm{~mL}$ centrifuge tube under acidified conditions with $1.0 \mathrm{~mL}$ of $6.0 \mathrm{~N}$ hydrochloric acid and dry ice coated. The volume of the $24 \mathrm{~h}$ urine output of each rat was measured and stored at $-80^{\circ} \mathrm{C}$ until analyzed. On the day of the assay, urine was thawed and centrifuged $3,000 \times$ g in the cold $\left(4^{\circ} \mathrm{C}\right)$ for $10 \mathrm{~min}$. Animals were sacrificed at the end of the study period and right kidneys were taken for immune histochemical evaluation. The selection of the site did not have any preference priority. It is just selected randomly.

\section{Evaluations}

\section{Urine 8-hydroxydeoxyguanosine measurement}

Urinary 80HdG was measured using an ELISA kit (OxiSelect ${ }^{\mathrm{TM}}$ Oxidative DNA Damage ELISA Kit, Cell Biolabs Inc., USA). Calibration, curve fitting and data analysis were conducted according to the manufacturer's instructions. Results are expressed ng/ml. The kit has an $8-0 H d G$ detection sensitivity range of $100 \mathrm{pg} / \mathrm{mL}$ to $20 \mathrm{ng} /$ $\mathrm{mL}$.

\section{Urine oxalate measurement}

Urine oxalate excretion was measured spectrophotometrically using an automated analyzer (COBAS INTEGRA 400) for clinical chemistry. For analysis, commercial kit (Oxalate, BEN-Biochemical Enterprise, Italy) was used. Calibration and data analysis were conducted according to manufacturer's instructions. Results were expressed as mg oxalate/gr creatinine/24 hours. Intra-assay CV for urine creatinine was $.7 \%$ and inter-assay CV was $1.0 \%$. The normal daily urinary oxalate excretion is about $.45-.9 \mathrm{mg} /$ day in rats [28]. Urine creatinine was measured with commercial kit (Roche Diagnostics GmbH, Germany) using COBAS INTEGRA 400 automatic analyzer. Results were expressed as $\mathrm{mg} / \mathrm{dL}$. Inter-assay CV for urine creatinine was $1.6 \%$ and intra-assay CV was .8\%.

\section{Immunohistochemical study and evaluation}

After routine tissue processing, the tissues were embedded in paraffin and $4 \mu \mathrm{m}$ thick 5 sections were prepared from each block for the immunohistochemistry. After deparaffinization, the slides for Fas (Anti Fas, dilution 1:100, BP1-41407, Novus Biologicals) and TNF-alpha (NB171668, dilution 1:100, Novus Biologicals Littleton, CO, USA) were processed according to manufacturer's instructions. Sections were counter-stained with haematoxylene, cleaned and mounted. Positive control studies were performed simultaneously in sections of human breast and colonic adenocarcinoma sections. Brown staining in cytoplasm was considered as "positive" and no staining as "negative" for each antibody. The number of both negative and positive tubular cells was counted in cortical tubules, medullar tubules and tubules in renal papillary region on each slide using Leica DM 6000 Digital microscope. For each slide, "percent expression" was calculated by dividing positive cells to the total number of counted cells, multiplied by 100 . The number of positive cells was determined by 1 pathologist blinded to the experimental groups. Immunohistochemical staining degree was scored on a scale of 0-negative, 1-mild, 2-moderate and 3-dense staining.

\section{Statistical analysis}

Statistical data were analyzed by SPSS $₫ 15.0$ for Windows $®$. Comparisons between groups were done using the Student's t test. Repeated measures of ANOVA were used for comparing within group changes of 8-OHdG and oxalate in time. Statistical significance considered at $\mathrm{p}<.05$. Results are shown as the mean \pm SD. 


\section{Results}

\section{The amount of urinary oxalate excretion}

Hyperoxaluria was confirmed by urinary excretion which was higher than control group throughout the study protocol $(40.2 \pm 12.9,217.3 \pm 144.6,742.6 \pm 275.7,335.3 \pm 131.0 \mathrm{mg}$ oxalate/gr creatinine/day, for controls, 24-hour, 14-day and 28-day samples, respectively). It began to increase 24 hour after exposure to ethylene glycol but highest level was observed at $14^{\text {th }}$ day and its level steadily decreased throughout the end of the study period but was still higher than control group and 24-hour samples ( $\mathrm{p}=.004$ and $p=.08$, respectively) (Figure 1 ).

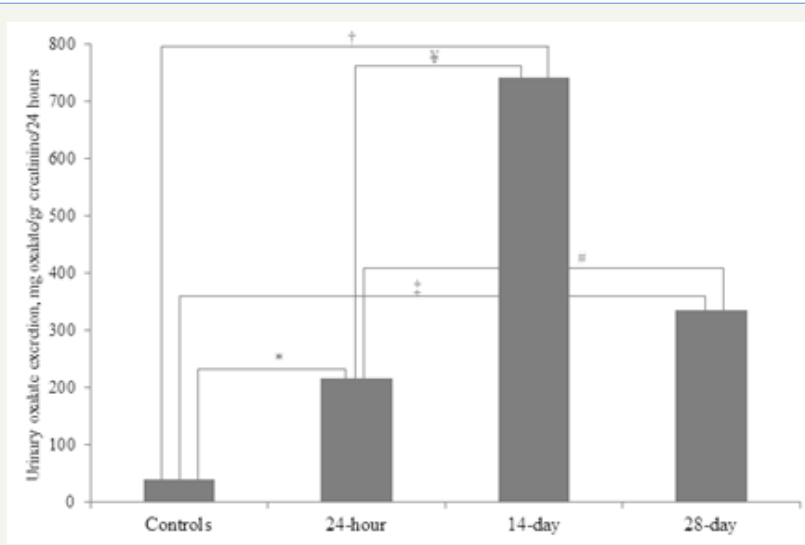

Figure 1: Urinary oxalate excretion rate in study population. It was significantly lower in controls compared to hyperoxaluric group. Urinary oxalate excretion was significantly increased through midperiod of the study duration and it steadily decreased at the end of the study period but was still higher than 24-hour and control group. $\left({ }^{*} 0,01, \dagger<0,0001, \ddagger 0,0002, ¥ 0,0003, \# 0,002\right)$.

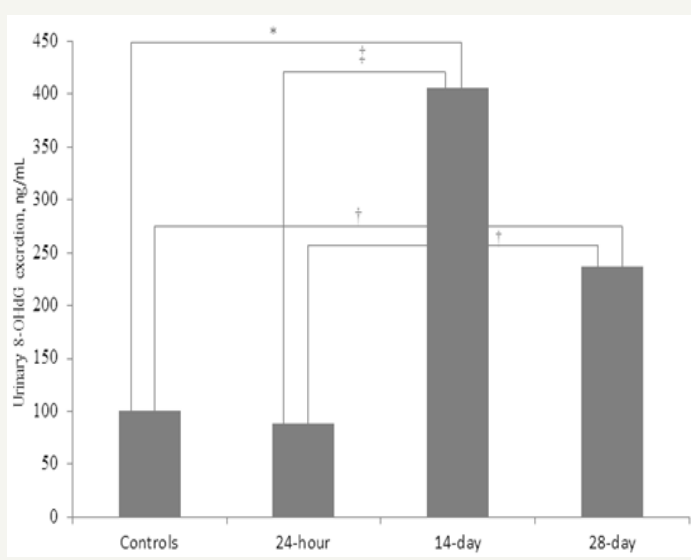

Figure 2: Urinary 8-hydroxyguanosine excretion rate in study population. It was similar to controls in the early samples of hyperoxaluric group. It significantly rise in 14 day samples and although decreased retained the higher level at the end of the study period. $\left({ }^{*} 0,01, \dagger<0,0001\right.$, $\ddagger 0,005)$.

\section{The results of oxidative DNA damage}

Increase in urinary 8-OHdG excretion was observed starting from day 14 . Early 24-hour samples were not different than control group $(100.4 \pm 8.7 \mathrm{ng} / \mathrm{mL}$ and $88.72 \pm 15.8 \mathrm{ng} / \mathrm{mL}$, respectively, $\mathrm{p}=.1$ ). At day $14,8-\mathrm{OHdG}$ levels were found to be increased in a statistically significant manner $(406.7 \pm 263.4 \mathrm{ng} / \mathrm{mL}, \mathrm{p}=.012)$. The level remained similar at the end of the study period $(237.7 \pm 53.8 \mathrm{ng} /$ $\mathrm{mL})$ and were higher than control $(\mathrm{p}<.0001)$ and 24-hour samples $(\mathrm{p}<.0001)$ but similar to 14-day samples $(\mathrm{p}=.09)$ (Figure 2$)$.

\section{Results of tissue immunohistochemical staining}

Immunohistochemical staining patterns of renal tubules in hyperoxaluric and control rats were demonstrated in Table1. Both TNF- $\alpha$ and Fas expression was higher in hyperoxaluric group compared to controls. Immunohistochemical staining in control group showed a negative $(0)$ to mild $(1+)$ pattern. Most of the staining pattern in hyperoxaluric group was moderate to dense $(2+$ or $3+$ ) for TNF- $\alpha$ and moderate $(2+)$ for Fas.

Table 1: Immuno histochemical staining patterns of renaltubules in hyperoxaluric and control rats.

\begin{tabular}{|c|c|c|c|}
\hline \multicolumn{2}{|c|}{ Control Group } & \multicolumn{2}{c|}{ Hyperoxaluric Group } \\
\hline TNF- $\boldsymbol{\alpha}^{*}$ & Fas** $^{* *}$ & TNF- $\boldsymbol{\alpha}^{*}$ & Fas $^{* *}$ \\
\hline 0 & $2+$ & $3+$ & $3+$ \\
\hline 0 & 0 & $3+$ & $2+$ \\
\hline 0 & 0 & $2+$ & $2+$ \\
\hline 0 & 0 & $2+$ & $2+$ \\
\hline 0 & $1+$ & $2+$ & $1+$ \\
\hline 0 & $1+$ & $2+$ & $2+$ \\
\hline 0 & $1+$ & $2+$ & $1+$ \\
\hline 0 & $1+$ & $2+$ & $1+$ \\
\hline
\end{tabular}

${ }^{*} \mathrm{p}<0,0001,{ }^{* *} \mathrm{p}=0,004$.

\section{Correlation analysis}

Urinary oxalate excretion rate was positively correlated with urinary 8-OHdG excretion ( $\mathrm{p}=.004, \mathrm{r}=.884$ ) (Figures 3 \& 4). There was also a positive correlation between urinary oxalate excretion and renal tissue cytokine expression rate. Urinary oxalate was positively correlated with tissue TNF- $\alpha(\mathrm{p}=.01, \mathrm{r}=.828)$ and Fas $(\mathrm{p}=.009, \mathrm{r}=.838)$. Urinary $8-0 \mathrm{HdG}$ excretion was also positively correlated with tissue TNF- $\alpha(\mathrm{p}=.03, \mathrm{r}=.734)$ and Fas $(\mathrm{p}=.01, \mathrm{r}=$ .821).

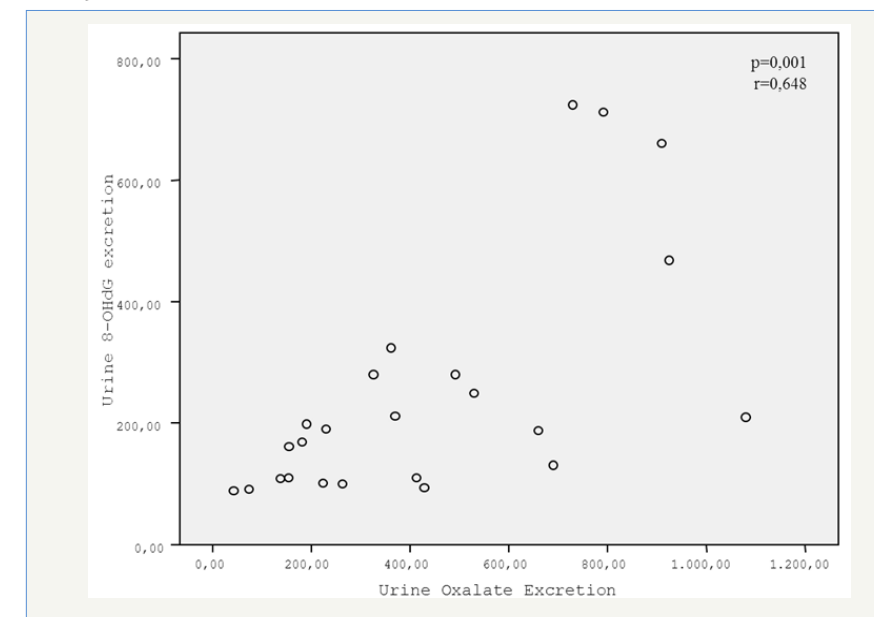

Figure 3: Urine excretion of $8-\mathrm{OHdG}$ was positively correlated with urine oxalate excretion. 


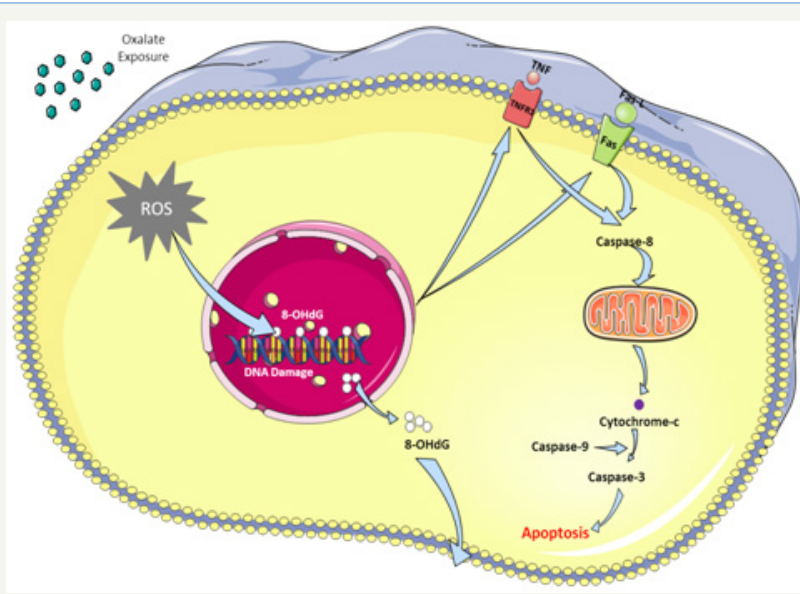

Figure 4: Graphical Abstract: Exposure to oxalate causes an increase in the production or reactive oxygen species (ROS) within the cell. Oxidative stress induces DNA damage and its product 8 -OHdG can be measured in the circulation. DNA damage, in turn, results in expression of death receptors (TNF-R1, Fas, TRIAL vb.) on cell surface. Coupling with the ligands causes activation of caspase system and finals with apoptosis.

\section{Discussion}

There are studies in the literature that show an increased 8-OHdG in patients with urolithiasis. But, for the first time, it was demonstrated in our study that it is directly resulted from hyperoxaluria. Calcium oxalate stone formation begins with the attachment of supersaturated crystals to the surface of renal tubular epithelial cells. In healthy people, these crystals are digested by macrophages and/or lysosomes inside of cells and rest of them are discharged in the urine. However, in individuals with hyperoxaluria, renal tubular cells are injured and crystals easily become attached to them. Various factors are thought to be involved in renal tubular epithelial injury. Direct toxic effect of oxalate [26], deposition of oxalate by epithelial cells [29], reduction in urinary macromolecules [30], oxidative stress and lipid peroxidation [31] are some of them. Oxidative stress is a common intersector in many pathological states. Several studies have provided evidence that oxalate-induced renal tubular cytotoxicity is closely related to superoxide and lipid peroxidation [27,31]. Increase in oxidative stress markers in the circulation and tissue level had been shown in various studies $[32,33]$. The use of antioxidants was successful in preventing crystal induced tubular cell injury in some studies [20]. The systemic use of antioxidants in humans, on the other hand, did not have enough satisfying results in preventing the development of renal stone disease [34,35].

Oxidative stress induces a process of cell damage by interacting with phospholipids, proteins, and nucleic acids ending with the death of the cell. Molecules formed during this process are used as biomarkers of oxidative damage which differ according to molecules involved. Widely used biomarker of oxidative damage to phospholipids is 8-iso prostaglandin F2 $\alpha$, o-tyrosine, 3 -chlorotyrosine, and 3-nitrotyrosine are biomarkers of protein oxidative damage, and damage to nucleic acids causes an increase in 8-hydroxy-2'-deoxyguanosine and 8-hydroxyguanosine in body fluids. These biomarkers were studied in different physiological for example ageing and pathological conditions such as Alzheimer's disease, arthritis, atherosclerosis, cataracts, hypertension, osteoporosis and type 2 diabetes [8,11,12,14-17,36-38]. There is no study on 8 -iso prostaglandin F2 $\alpha$ in urolithiasis. Only one study exists in the literature on the effect of 3-nitrotyrosine together with atherogenic inflammatory markers in patients with urolithiasis and reported elevated levels which might be a possible pathogenetic link in complications and systemic elongations of urolithiasis [25].

Although limited, 8-hydroxyguanosine is the most widely studied molecule among others. Both tissue and circulating 8-OHdG levels had been shown to be elevated in patients with urolithiasis [24,26,39]. Boonla et al. [24] studied urinary 8-hydroxyguanosine excretion in patients with urolithiasis and reported significantly elevated levels. On the other hand, Ke et al. [40] studied on melamin exposed children. Although a significant correlation between urolithiasis and percentage of melamin exposure detected, there were no correlation between percentage melamin intake and 8-hydroxyguanosine [41]. The link between hyperoxaluria, oxidative damage and apoptosis was studied by Zhai et al. [41] Their study had two parts: hyperoxaluria induced by ethylene glycol in rats resulted in increased expression of 8-hydroxyguanosine, malondialdehyde and superoxide dismutase in renal tubular cells and in cell culture study they found an increased caspase- 3 activity [41]. Results indicate that hyperoxaluria induces oxidative DNA damage and apoptosis in renal tubules similar to our findings.

Renal tubular epithelial injury results in death of tubular cells which is the preceding nidus for the attachment of crystals to the epithelial cells Apoptosis and necrosis are two different types of cell death seen in different conditions. Oxalate-induced death of renal epithelial cells exhibits several features characteristic of apoptotic cell death [42]. Several different biomolecules are described as inducers of apoptosis such as chemical compounds, proteins etc. The biochemical pathways of apoptosis are complex and depend on both the cells and the inducers. Some of the inducers include Fas/ Fas-ligand, caspase-8, TNF- $\alpha$ /TNFR1, TRAIL/TRAILR1 and R2 [4346]. We have shown in one of our latest studies that hyperoxaluria induces apoptosis and TNF- $\alpha$ /TNFR1 and Fas/Fas-L pathways dominate the event. TRAIL/TRAILR2 did not have any role in this process [47]. Increase in caspase- 3 expression was also reported in two different studies $[41,48]$. Caspase-3 is an important molecule in cellular apoptosis. It is located within the cell and extrinsic or intrinsic signals can induce its levels and result in apoptosis. Hyperoxaluria is an extrinsic event inducing this cascade. TNF- $\alpha$ / TNFR1 and Fas/Fas-L are cell surface receptors and coupling results in activation of caspase- 8 which then activates caspase-3. The question here is whether cell surface apoptosis markers are correlated with oxidative DNA damage. In our study, we tried to clarify this relationship. We found that hyperoxaluria induced oxidative DNA damage and increased expression of TNF- $\alpha$ and Fas on renal tubular cells. These findings strengthen the results of our previous findings and study done by Zhai et al. [41].

Oxidative DNA damage was not only limited to renal tubular epithelial cells in our study since urine excretion of 8-OHdG refers

How to cite this article: Hasan A, Faruk Y, Jale Ç, Hasbey H K .Hyperoxaluria Induces Oxidative DNA Damage and Results in Renal Tubular Epithelial Cell 
to systemic damage to DNA. As evident from previous studies that showed increased 8-OHdG excretion in systemic diseases like diabetes mellitus, atherosclerosis [11,17] urinary excretion of 8-OHdG reflects total body DNA damage. Increased expression of apoptotic markers in renal tubular tissue samples in correlation with 8-OHdG might indicate it to be a mediator of apoptosis in urolithiasis.

Urolithiasis had been shown to be related to several diseases such as obesity, diabetes mellitus, metabolic syndrome and hyperlipidemia which are also very well-known inducers of oxidative stress and oxidative DNA damage [49-52]. Several hypotheses have been proposed to explain the pathophysiology of urolithiasisaccompanying these systemic diseases. Although obesity, overweight, and sedentary lifestyles have been identified as major etiological factors [52], none of them have any direct link to how they contribute to renal stone formation. Our results may also highlight the etiology or at least add on it. The relevant hypothesis might be like this: 1) systemic diseases induce generalized oxidative stress in the body 2) this eventually creates oxidative damage to DNA in tissues 3) since all of these diseases are also closely related to hyperoxaluria, calcium oxalate crystal easily attaches to these injured renal tubular epithelial cells and 4) stone formation begins.

Oxidative DNA damage was not evident in early (24 hour) samples but started to increase in a moderate time period. This makes a sense because tissue injury takes time. The results show that hyperoxaluria does not have an acute effect. Also, as the oxalate excretion decreased, parallel to it, 8-OHdG excretion decreased also. This finding shows that tissue injury or oxidative DNA damage is directly related to the degree of hyperoxaluria.

There are some limitations of the study. It might be better to lengthen the observation period in the study to see long term effects. But, follow-up period in our study was comparable to most of the previous studies designed similarly. It can be satisfying to observe the effect of hyperoxaluria. The result might not always provide evidence that hyperoxaluria directly induces oxidative DNA damage, since only one marker has been taken in the study. Studies on other markers will strengthen the results of our study. The aim of this study was to observe the effect of hyperoxaluria on oxidative DNA damage and renal tubular cell apoptosis. The exact mechanism of how hyperoxaluria induces DNA damage and apoptosis is subject of another study.

\section{Conclusion}

This study demonstrates induction of oxidative damage to DNA by hyperoxaluria and its relationship with renal tubular epithelial cell apoptosis. These findings may add to the exact pathophysiology of renal stone disease and help to explain the association of systemic diseases with urolithiasis.

\section{References}

1. Halliwell B, Cross CE (1994) Oxygen-derived species: their relation to human disease and environmental stress. Environ Health Perspect 102(Suppl 10): 5-12.
2. Dizdaroglu M (1993) Quantitative determination of oxidative base damage in DNA by stable isotope-dilution mass spectrometry. FEBS Lett 315(1): 1-6.

3. Dizdaroglu M (1986) Free-radical-induced formation of an 8, 5V-cyclo2Vdeoxyguanosine moiety in deoxyribonucleic acid. Biochem J 238: 247-254.

4. Loft S, Vistisen K, Ewertz M, Tjonneland A, Overvad K, et al. (1992) Oxidative DNA damage estimated by 8-hydroxydeoxyguanosine excretion in humans: influence of smoking, gender and body mass index. Carcinogenesis 13(12): 2241-2247.

5. Nilsson R, Nordlinder R, Tagesson C, Walles S, Jarvholm BG (1996) Genotoxic eVects in workers exposed to low levels of benzene from gasoline. Am J Ind Med 30(3): 317-324.

6. Marczynski B, Rozynek P, Elliehausen HJ, Korn M, Baur X (1997) Detection of 8-hydroxydeoxyguanosine, a marker of oxidative DNA damage, in white blood cells of workers occupationally exposed to styrene. Arch Toxicol 71(8): 496-500.

7. Tagesson C, Chabiuk D, Axelson O, Baranski B, Palus J, et al (1993) Increased urinary excretion of the oxidative DNA adduct, 8-hydroxydeoxyguanosine, as a possible early indicator of occupational cancer hazards in the asbestos, rubber, and azo-dye industries. Pol J Occup Med Environ Health 6(4): 357-368.

8. Kuo HW, Chang SF, Wu KY, Wu FY (2003) Chromium (VI) induced oxidative damage to DNA: increase of urinary 8-hydroxydeoxyguanosine concentrations (8-OHdG) among electroplating workers. Occup Environ Med 60(8): 590-594.

9. Nilsson R, Nordlinder R, Moen BE, Øvrebø S, Bleie K, et al. (2004) Increased urinary excretion of 8-hydroxydeoxyguanosine in engine room personnel exposed to polycyclic aromatic hydrocarbons. Occup Environ Med 61(8): 692-696.

10. Valavanidis A, Vlachogianni T, Fiotakis C (2009) 8-hydroxy-2deoxyguanosine (8-OHdG): A Critical Biomarker of Oxidative Stress and Carcinogenesis. J Environ Sci Health Part C 27: 120-139.

11. Nishikawa T, Sasahara T, Kiritoshi S, Sonoda K, Senokuchi T, et al. (2003) Evaluation of urinary 8-hydroxydeoxy-guanosine as a novel biomarker of macrovascular complications in type 2 diabetes. Diabetes Care 26(5): $1507-1512$.

12. Lezza A, Mecocci P, Cormio A, Beal MF, Cherubini A, et al. (1999) Areaspecific differences in $0 \mathrm{H} 8 \mathrm{dG}$ and mtDNA4977 levels in Alzheimer disease patients and aged controls. J Anti-Aging Med 2: 209-215.

13. Alam ZI, Jenner A, Daniel SE, Lees AJ, Cairns N, et al. (1997) Oxidative DNA damage in the parkinsonian brain: an apparent selective increase in 8-hydroxyguanine levels in substantia nigra. J Neurochem 69(3): 1196-1203.

14. Shimoda R, Nagashima M, Sakamoto M, Yamaguchi N, Hirohashi $S$, et al. (1994) Increased formation of oxidative DNA damage, 8-hydroxydeoxyguanosine, in human livers with chronic hepatitis. Cancer Res 54(12): 3171-3172.

15. Lunec J, Herbert K, Blount S, Griffiths HR, Emery P (1994) 8-Hydroxydeoxyguanosine. A marker of oxidative DNA damage in systemic lupus erythematosus. FEBS Lett 348(2): 131-138.

16. D'Inca R, Cardin R, Benazzato L, Angriman I, Martines D, et al. (2004) Oxidative DNA damage in the mucosa of ulcerative colitis increases with disease duration and dysplasia. Inflamm Bowel Dis 10(1): 23-27.

17. Martinet W, Knaapen MW, De Meyer GR, Herman AG, Kockx MM (2002) Elevated levels of oxidative DNA damage and DNA repair enzymes in human atherosclerotic plaques. Circulation 106(8): 927-932.

18. Loft S, Larsen PN, Rasmussen A, Fischer-NA, Bondesen S, et al. (1995) Oxidative DNA damage after transplantation of the liver and small intestine in pigs. Transplantation 59(1): 16-20. 
19. Rattan S, Siboska GE, Wikmar FP, Clark BFC, Woolley P (1995) Levels of oxidative DNA damage product 8-hydroxy-2V-deoxyguanosine in human serum increases with age. Med Sci Res 23: 469-470.

20. Kahn SR (2005) Hyperoxaluria-induced oxidative stress and antioxidants for renal protection. Urol Res 33(5): 349-357.

21. Kahn SR (2013) Reactive oxygen species as the molecular modulators of calcium oxalate kidney stone formation: evidence from clinical and experimental investigations. J Urol 189(3): 803-811.

22. Muthukumar A, Selvam R (1997) Renal injury mediated calcium oxalate nephrolithiasis: role of lipid peroxidation. Ren Fail 19(3): 401-418.

23. Kahn SR (2013) Stress oxidative: nephrolithiasis and chronic kidney diseases. Minerva Med 104(1): 23-30.

24. Boonla C, Wunsuwan R, Tungsanga K, Tosukhowong P (2007) Urinary 8-hydroxydeoxyguanosine is elevated in patients with nephrolithiasis. Urol Res 35(4): 185-191

25. Tsao KC, Wu TL, Chang PY, Sun CF, Wu LL, et al. (2007) Multiple Risk Markers for Atherogenesis Associated With Chronic Inflammation Are Detectable in Patients With Renal Stones. J Clin Lab Anal 21(6): 426-431.

26. Strzelecki T, McGraw BR, Scheid CR, Menon M (1989) Effect of oxalate on function of kidney mitochondria. J Urol 141(2): 423-427.

27. Thamilselvan S, Hackett RL, Khan SR (1997) Lipid peroxidation in ethylene glycol induced hyperoxaluria and calcium oxalate nephrolithiasis. J Urol 157(3): 1059-1063.

28. Marengo SR, Chen DH, Evan AP, Sommer AJ, Stowe NT, et al. (2006) Continuous infusion of oxalate by minipumps induces calcium oxalate nephrocalcinosis. Urol Res 34(3): 200-210.

29. Hackett RL, Shevock PN, Khan SR (1995) Alterations in MDCK and LLCPK1 cells exposed to oxalate and calcium oxalate monohydrate crystals. Scanning Microsc 9(2): 587-596.

30. Tsujihata M, Tsujikawa K, Tei N, Yoshimura K, Okuyama A (2006) Urinary macromolecules and renal tubular cell protection from oxalate injury: comparison of normal subjects and recurrent stone formers. Int J Urol 13(3): 197-201.

31. Scheid C, Koul H, Hill WA, Luber-NJ, Kennington L, et al. (1996) Oxalate toxicity in LLC-PK1 cells: role of free radicals. Kidney Int 49(2): 413-419.

32. Bet VV, Deshpande KH, Suryakar AN, Ankush RD, Katkam RV (2006) Depleted nitrite and enhanced oxidative stress in urolithiasis. Indian J Clin Biochem 21(2): 177-180.

33. Park HK, Jeong BC, Sung MK, Park MY, Choi EY, et al. (2008) Reduction of oxidative stress in cultured renal tubular cells and preventive effects on renal stone formation by the bioflavonoid quercetin. J Urol 179(4): $1620-1626$

34. Theka T, Rodgers A, Lewandowski S, Webber D, Allie-HS (2012) Effects of vitamin $\mathrm{E}$ ingestion on plasma and urinary risk factors for calcium oxalate urolithiasis in two population groups having different stone-risk profiles: evidence of different physiological handling mechanisms. Urol Res 40(2): 113-120.

35. Tracy CR, Henning JR, Newton MR, Aviram M, Bridget ZM (2014) Oxidative stress and nephrolithiasis: a comparative pilot study evaluating the effect of pomegranate extract on stone risk factors and elevated oxidative stress levels of recurrent stone formers and controls. Urolithiasis 42(5): 401-418.

36. Dincer Y, Himmetoglu S, Akcay T, Ersoy EY, Gunes KN, et al. (2007) Prognostic significances of oxidative DNA damage evaluated by 8-hydroxy-deoxyguanosine and antioxidant enzymes in patients undergoing resection of gastric and colon carcinoma. Neoplasma 54(2): 131-136.

37. Kroese LJ, Scheffer PG (2014) 8-hydroxy-2'-deoxyguanosine and cardiovascular disease: a systematic review. Curr Atheroscler Rep 16(11): p. 452.

38. Ock CY, Kim EH, Choi DJ, Lee HJ, Hahm KB, et al. (2012) 8-Hydroxydeoxyguanosine: not mere biomarker for oxidative stress, but remedy for oxidative stress-implicated gastrointestinal diseases. World J Gastroenterol 18(4): 302-328.

39. Syslová K, Böhmová A, Mikoška M, Kuzma M, Pelclová D, et al. (2014) Multimarker Screening of Oxidative Stress in Aging. Oxid Med Cell Longev 2014(2014).

40. Ke Y, Duan X, Wen F, Xu X, Tao G, et al. (2010) Association of melamine exposure with urinary stone and oxidative DNA damage in infants. Arch Toxicol 84(4): 301-317.

41. Zhai W, Zheng J, Yao X, Peng B, Liu M, et al. (2013) Catechin prevents the calcium oxalate monohydrate induced renal calcium crystallization in NRK-52E cells and the ethylene glycol induced renal stone formation in rat. BMC Complement Altern Med 13: 228.

42. Miller C, Kennington L, Cooney R, Kohjimoto Y, Cao LC, et al. (2000) Oxalate toxicity in renal epithelial cells: characteristics of apoptosis and necrosis. Toxicol Appl Pharmacol 162(2): 132-141.

43. Jung JY, Kim WJ (2004) Involvement of mitochondrial- and Fas-mediated dual mechanism in $\mathrm{CoCl}_{2}$-induced apoptosis of rat PC12 cells. Neurosci Lett 371(2-3): 85-90.

44. Kuwana T, Smith JJ, Muzio M, Dixit V, Newmeyer DD, et al. (1998) Apoptosis induction by caspase-8 is amplified through the mitochondrial release of cytochrome c. Journal of Biological Chemistry 273: 1658916594.

45. MacFarlane M, Ahmad M, Srinivasula SM, Fernandes-AT, Cohen GM, et al. (1997) Identification and molecular cloning of two novel receptors for the cytotoxic ligand TRAIL. J Biol Chem 272(41): 25417-25420.

46. Sutheesophon K, Nishimura N, Kobayashi Y, Furukawa Y, Kawano M, et al. (2005) Involvement of the tumor necrosis factor (TNF)/TNF receptor system in leukemic cell apoptosis induced by histone deacetylase inhibitor depsipeptide (FK228). J Cell Physiol 203(2): 387-397.

47. Horuz R, Göktaş C, Çetinel CA, Akça O, Aydın H, et al. (2013) Role of TNF-associated cytokines in renal tubular cell apoptosis induced by hyperoxaluria. Urolithiasis 41(3): 197-203.

48. Sahin C, Sarikaya S, Basak K, Cetinel CA, Narter F, et al. (2015) Limitation of apoptotic changes and crystal deposition by Tutukon following hyperoxaluria-induced tubular cell injury in rat model Urolithiasis 43(4): 313-322.

49. Aydogdu 0 (2012) Urinary stone disease and obesity: Different pathologies sharing common biochemical mechanisms. World J Nephrol 1(1): 12-15.

50. Liu LH, Kang R, He J, Zhao SK, Li FT, Zhao ZG (2015) Diabetes mellitus and the risk of urolithiasis: a meta-analysis of observational studies. Urolithiasis 43(4): 293-301.

51. Masterson JH, Woo JR, Chang DC, Chi T, L Esperance JO, Stoller ML, et al. (2015) Dyslipidemia is associated with an increased risk of nephrolithiasis. Urolithiasis 43(1): 49-53.

52. Wong YV, Cook P, Somani BK (2015) The association of metabolic syndrome and urolithiasis. Int J Endocrinol 2015(2015): 570674.

How to cite this article: Hasan A, Faruk Y, Jale Ç, Hasbey H K .Hyperoxaluria Induces Oxidative DNA Damage and Results in Renal Tubular Epithelial Cell 